\title{
Meckel-Gruber Syndrome
}

National Cancer Institute

\section{Source}

National Cancer Institute. Meckel-Gruber Syndrome. NCI Thesaurus. Code C98978.

A rare, lethal, autosomal recessive inherited syndrome characterized by pulmonary

hypoplasia, central nervous system malformations, and hepatic malformations. 